\title{
SPATIAL PREDICTION MODELS FOR LANDSLIDE ACTIVITY MAPPING USING VEGETATION ANOMALIES
}

\author{
Mohd Radhie Mohd Salleh ${ }^{1}$, Zamri Ismail ${ }^{1}$, Shakirah Amirah Binti Mohd Ariff ${ }^{1}$, Muhammad Zulkarnain Abd Rahman ${ }^{1 *}$, Mohd $^{*}$ \\ Faisal Abdul Khanan ${ }^{1}$, Mohd Asraff Asmadi ${ }^{1}$, Khamarrul Azahari Razak ${ }^{2}$ \\ ${ }^{1}$ Department of Geoinformation, Faculty of Built Environment and Surveying, Universiti Teknologi Malaysia, Johor- \\ mohdradhie.gis@gmail.com, zamriismail@utm.my, samirah33@utm.my, mdzulkarnain@utm.my, mdfaisal@utm.my, \\ asraff65@gmail.com \\ ${ }^{2}$ UTM Razak School of Engineering and Advanced Technology, Universiti Teknologi Malaysia, Kuala Lumpur - \\ khamarrul.kl@utm.my
}

KEY WORDS: Tropical rain forest, Landslide activity, Vegetation anomalies, Remote Sensing

\begin{abstract}
:
An area that located in Kundasang which in Ranau district in Sabah, Malaysia that lies along the bank of Kundasang valley was chosen for comparing the reliability of frequency ratio (FR) and weight of evidence (WoE) methods for landslide activity probability mapping by using related vegetation anomalies indicator. The locations of 47 and 189 of active and dormant landslides respectively were identified using 4 raster layers (topographic openness, hillshade, colour composite and high resolution orthophoto). Each landslide activites were randomly divided into two groups as training $(70 \%)$ and testing $(30 \%)$ datasets. Tree height irregularities, DVI, NDVI, SAVI, and OSAVI were considered as landslide bio-indicator. The landslide activity probability maps were prepared using the FR and WoE method. The generated maps were validated by calculating the success and prediction rates from area under receiver operating characteristics (ROC) curve. The results of WoE method were relatively reliable (AUC > 0.8) for dormant landslide while only about $40 \%$ of active landslide have been predicted accurately. Similar trend yielded for FR method where least accuracy for active landslide prediction.
\end{abstract}

\section{INTRODUCTION}

Landslide is major problem that required attention. Landslide is rapid movement downward cause by collapse of a mass of rock or earth from mountain or cliff. It can be triggered by natural activity i.e. earthquake, heavy rainfall or human intervention such as deforestation. Snowmelt or heavy rainfall may affect the structure and mechanical stability of the ground and human activity such as mining and deforestation may cause landslide by making the soil vulnerable to oversaturation and erosion. Generally, landslides are predict to happen in the future under the same conditions (Guzzetti et al., 1999; Lepore et al., 2012; Skilodimou et al., 2018). Therefore, landslide inventory map considered as one of the most important elements for landslide studies.

In general, a landslide inventory map provides basic information such as location of mass movements and the date of occurrences (Hansen, 1984; McCalpin, 1984; Guzzetti et al., 2012). Landslide inventory can be used for multiple purpose such as (1) recording the magnitude of landslide in a region, (2) performing the initial steps in analyzing the susceptibility, hazard, and risk of the landslide, and (3) examining the patterns of landslide distributions and studying the evolution of landscape affected by landslides (Rosi et al., 2018). It also contains a collection of polygon shapes, types, lengths, widths, areas, locations, and other information related to landslides (Pirasteh \& Li, 2018). This map provides spatial and temporal distribution of landslide patterns, type of movement, type of displaced material (earth, debris or rock), rate of movement etc.
With such valuable information, landslide inventory data can be integrated in GIS environment (Martha et al., 2010; Lyons et al., 2014). This implementation enables us to increase the level of understanding of landslide phenomena across regions and through space and time (Wood et al., 2015). Moreover, landslide inventory map represented as fundamental element in a framework for accessing landslide susceptibility, hazard, and risk (Pellicani \& Spilotro, 2015).

However, one of the challenges of producing landslide inventory map is due to the rapid vegetation growth especially in tropical region such as Malaysia. Conventional methods have constrained due to low coverage which require aerial photograph, the availability of geomorphologists experienced in recognition of landslides from aerial images and in the field, and the time and resources needed to complete the inventory (Guzzetti et al., 2012). In addition, field survey method is time consuming and resource intensive procedure (Guzzetti et al., 1999; Haneberg, Cole, \& Kasali, 2009; Pawluszek, Borkowski, \& Tarolli, 2017). Recently, new methods and technologies have been exploited by researchers in detect and map the landslides (Guzzetti et al., 2012). One of the technologies used is airborne LiDAR (Light Detection and Ranging).

The ability of high density airborne LiDAR data to penetrate the vegetation in providing the topographic surface is significant to detect and map the landslide under forested area (Haugerud et al., 2003; Van Eeckhaut, M., et al., 2007; Booth et al., 2009; Bibi et al., 2017). LiDAR derivative products such as contour maps, shaded relief, slope, curvature etc. can be further used in landslide detection and mapping (Guzzetti et al., 2012;

Corresponding author 
Jaboyedoff et al., 2012; Bibi et al., 2017). Nevertheless, the main limitations of this technique are the cost of data acquisition (Joyce et al., 2014; Gaidzik et al., 2017) and time consuming for data processing especially for large areas. As a result, most of the studies generally covered small area (less than $\left.20 \mathrm{~km}^{2}\right)$ (Guzzetti et al., 2012).

Landslide activity analysis is a crucial aspect of landslide inventory mapping and it is even more challenging in forested rugged terrain. Conventionally, an interpreter can recognize landslide type and activity based on several diagnostic features such as morphology. For instance, active slides are commonly fresh; that is, their morphological features, such as scarps and ridges, are easily recognizable as being due to gravitational movement, and they have not been significantly modified by surficial processes of weathering and erosion (Varnes, 1978). Remote sensing technologies such as synthetic aperture radar (SAR) sensors primarily to measure surface deformations, and to construct time series of surface deformations, at single points (Berardino et al., 2002; Hooper et al., 2007; Cigna et al., 2011; Jaboyedoff et al., 2012; Bianchini et al., 2017;).

However, this method is an active sensor and the data acquisition depend on various factor such as natural illumination, foreshortening, layover effects, atmosphere propagation effects, and vegetation decorrelation in forested terrain (Rott, 2009; Scaioni, Longoni, Melillo, \& Papini, 2014). Besides that, the techniques of geomatics also widely used for landslide activity analysis (Artese \& Perrelli, 2018).

In Malaysia, landslide analysis tends to have frequent site visit, and real-time monitoring of the deformation that can cause lots of budget to be put on, and potential hazard to property and life once the landslide struck. Expensive instrument such as total station (the integration of a theodolite and an electronic distance meter (EDM)) was installed in landslide area for monitoring purpose (Stiros et al., 2004; Tsai et al., 2012; Afeni \& Cawood, 2013; Castagnetti et al., 2013; Corsini et al., 2013; Simeoni et al., 2015). However, this method is high risk especially for active fault areas which will damage the instruments. For this reason, the implementation of vegetation anomalies as one of the landslide activity indicators can lead as an effective approach. Landsliding may damage trees and produce silent witnesses. Trees as silent witnesses may be displaced, tilted, partially buried, bended, or limited in growth by landslides.

Using this study, problems arising from implementing conventional and other recent methods can be kept to a minimum, as utilizing remote sensing technology enables the researcher to obtain vegetation anomalies as a bio-indicator of landslide activity mapping and analysis. In addition, this studies also capable in defining the method to produce vegetation anomalies from remote sensing data and analyze the performance of geospatial-based approach. A vegetation anomaly characteristics library can be developed as a guideline to landslide activity monitoring and mapping in Malaysia, and Kundasang in particular. This is because, despite its use as one of the slopes strengthening methods, it can be used as a bioindicator of defining landslides in different type, depth and activity.

\section{STUDY AREA}

\subsection{Description of Study Area}

The study area is is located at Kundasang, Sabah, Malaysia $\left(5^{\circ} 59^{\prime} 0.69^{\prime \prime} \mathrm{N}, 116^{\circ} 34^{\prime} 43.50 " \mathrm{E}\right)$, in the Northern part of Sabah. Kundasang is a town in Ranau district that lies along the bank of Kundasang Valley. It is the closest town to Mount Kinabalu and has a panoramic view of the Mountain. With an elevation of almost $1,900 \mathrm{~m}(6,200 \mathrm{ft})$, it is the highest settlement in Malaysia.

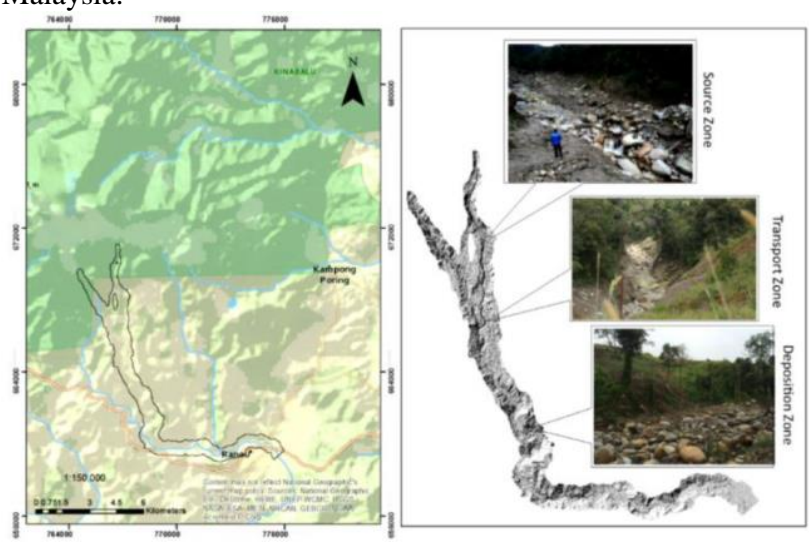

Figure 1. Location of study area at Mesilau River in Kundasang region which was struck by debris flow in June 2015

The area is in a typical tropical climate, large amount of rainfall throughout the year. The annual rainfall ranges from $1920 \mathrm{~mm}$ to $3190 \mathrm{~mm}$ (average $2075 \mathrm{~mm}$ ) (Tating et al., 2013). Kundasang area consists of three (3) types of lithology; Pinasouk gravel, Trusmadi formation and Crocker formation. On 5 June, an earthquake measuring 6.0 Mw occurred in Sabah that had triggered the debris flow which caused the disruption of roads, houses and the vegetation along the channel. It is said that the earthquake was caused by movement on a SoutwestNortheast (SW-NE) trending normal fault and the epicenter was near Mount Kinabalu.

The shaking caused massive landslides around the mountain (Tongkul, 2015). Rocks located beneath Kundasang vary in age and type, which are the rock starting from Paleocene-Eocene rocks to alluvial rock. Three formations are present and include Trusmadi Formation, Crocker Formation and Quaternary sediment (Tongkul, 1987). Mensaban fault zone is located on the eastern side of Kundasang area which intersects with Crocker fault. The mass movements in Kundasang area can be the result of active movement in Crocker and Mensaban fault zones.

\section{METHODOLOGY}

In general, the implemented methodology in this study contain five (5) main stages. The first stage concentrates on the data collection, which consists of field and remotely sensed data collection. The second stage emphasizes on the data preprocessing while the third phase focuses on delineating and characterizing landslides using remotely sensed data and fieldbased approach. In the fourth phase, the remotely sensed data was used to derive several vegetation anomalies indicators. The final phase focuses on generating the landslides activity maps that account different scenarios of landslide activity. These landslide activity maps were evaluated based on the area under receiver operating characteristics (ROC) curve. 


\subsection{Data Collection}

There are two types of data required to employ this study i.e. primary data and secondary data. Primary data includes field observation for selected landslide area with its vegetation characteristics. Meanwhile, secondary data consists of airborne LiDAR data collection, satelite imageries, aerial photograph, etc. Airborne LiDAR is an active sensor that will be used in this study. The scanning system known as Integrated Geospatial Innovations (IGI) Lite Mapper 6800-400 was mounted onto a helicopter, captured multiple returns of laser pulse of the terrain over debris flow along Mesilau River channel.

This data was captured in August 2015, approximately two months after the debris flow that hit the Mesilau River. This system combined the Laser Scanner 6800-400, IMU-Ilf Inertial Measurement Unit, Trimble R7 GPS Receiver, DigiCAM H60, DigiCAM Lens Cone HC 3,5/50-11, Clear-Protection-Filter, 77mm, LiteMapper system mount, LiteMapper Data Recorder 680 and AEROcontrol Sensor Management Unit.

The point cloud data were generated from a RIEGL LMS-Q680i airborne laser scanner (ALS), a long-range airborne laser scanner with full waveform analysis. RIEGL LMS-Q680i scanner provides scan data acquisition with $20 \mathrm{~mm}$ accuracy or $20 \mathrm{~mm}$ precision, maximum range of $3000 \mathrm{~m}$ and measurement up to 266,000 pulses per second on the ground, thus, producing a very high-density point cloud data (RIEGL $® 2012$ ). Average point density per meter square $\left(\mathrm{m}^{2}\right)$ in this study area is 160 points.

The satellite image used in this study is Pleiades. This satellite system is one of the recent satellite missions launched by French-Italian ORFEO system (Optical and Radar Federated Earth Observation). It is managed by Centre National d'Etudes Spatiales (CNES) and ASTRIUM Geo-Information Services (Gleyzes et al., 2012). Pleiades satellite system allows two satellite for a one-day revisit time worldwide. By comparing with other satellite system such as GeoEye-1 and WordView-2, Pleiades can provide wide coverage (a total of 1 million square kilometres daily) and similar spatial resolution (Poli et al., 2013). In term of satellite imageries properties, it consists of four spectral bands (blue, green, red, and NIR) as the planimetric accuracy approximately 3 meters without ground control points.

\subsection{Data Pre-processing}

Data pre-processing include correction and calibration of the airborne LiDAR data and satellite imageries. Filtering process also known as point cloud classification focus on the separation of point cloud into ground and non-ground returns (Q. Chen, 2007). Filtered point cloud is highly valuable for deriving the height of tree, building and other land features. The filtering process was carried out using Adaptive TIN Densification algorithm embedded in the Terrascan software. The ground points were interpolated to generate Digital Terrain Model (DTM). Digital Surface Model (DSM) was generated by taking the highest points within $25 \mathrm{~cm}$ moving window over the entire dataset. DTM was then substracted from DSM in order to produce Canopy Height Model (CHM) with $25 \mathrm{~cm}$ of spatial resolution.

\subsection{Landslide Inventory}

Landslide inventory provides basic information such as location of mass movements and the date of occurrences. Preparation of landslide inventory map is an imperative procedure of landslide study. LiDAR-derived raster layer that have been produced was then further applied for landslide interpretation. These raster layers were overlaid together with high resolution of aerial photograph. The delineation and characterization process of landslide was conducted by analyzing the terrain surface. Usually, a landslide area was characterized by hummocky surface, extreme curvature and concavity, sudden steep slope of the planar surface and clear color contrast of aerial photograph. A series of landslide validation were done to ensure the certainty level of the delineated landslide. This validation processes were done by visiting the landslide area and based on expert-knowledge.

\subsection{Estimation of Vegetation Anomalies}

Overall, five vegetation anomalies were derived as an indicator for landslide activity mapping. Airborne LiDAR and satellite imageries used to generate all the indicators such as Normalized Difference Vegetation Index (NDVI), Difference Vegetation Index (DVI), Soil Adjusted Vegetation Index (SAVI), Optimized Soil Adjusted Vegetation Index (OSAVI), and tree height irregularities.

\subsection{Generation of Landslide Activity Probability Map}

In this study, WoE and FR methods were applied to generate landslide activity probability map of the study area. The production of this map be carried out in a GIS-based system.

3.5.1 Frequency Ratio Method: The FR approach is a bivariate statistical method that is simple to implement (Lee \& Pradhan, 2007; Park et al., 2013). It is consider as quantitative technique by applying spatial data and GIS technique (Chen et al., 2016; Ding et al., 2017). The FR value is quantified by establish the combination between indicator and landslide inventory map (Reis et al., 2012) using Equation (1) (Mondal \& Maiti, 2013).

$$
F R=\frac{N p i x(1) / N p i x(2)}{\sum N p i x(3) / \sum N p i x(4)}
$$

$\operatorname{Npix}(1)=$ The number of pixels containing landslide in a class $\operatorname{Npix}(2)=$ Total number of pixels of each class in the whole area

$\sum \operatorname{Npix}(3)=$ Total number of pixels containing landslide $\sum \operatorname{Npix}(4)=$ Total number of pixels in the study area

The summation of FR value then used to develop landslide activity map (LAM) using Equation (2).

$$
\mathrm{LAM}=\mathrm{Fr}_{1}+\mathrm{Fr}_{2}+\mathrm{Fr}_{\mathrm{a}}+\mathrm{Fr}_{4}+\ldots \ldots+\mathrm{Fr}_{\mathrm{n}}
$$

where Fr is the frequency ratio, and $\mathrm{n}$ is the number of selected indicators.

3.5.2 Weight of Evidence (WoE): WoE method was originally developed by Bonham-Carter et al. (1988) for mineral potential assessment. This method is a probabilistic approach based on a log linear form of Bayes' rule as expressed in Equation (3) 


$$
(A \mid B)=P(B \mid A) x \frac{P(A)}{P(B)}
$$

This method calculates the weight for each landslide predictive factor (B) based on the presence or absence of the landslide (A) within the area

$$
\begin{aligned}
& W^{+}=\ln \left(\frac{P\{B \mid A\}}{P\{B \mid \bar{A}\}}\right) \\
& w^{-}=\ln \left(\frac{P\{\underline{B} \mid A\}}{P\{\underline{B} \mid \bar{A}\}}\right)
\end{aligned}
$$

where $\mathrm{P}$ is the probability and $\ln$ is natural $\log , \mathrm{B}$ is the presence of desired class of landslide causative factor, $\underline{B}$ is the absence of desired class of landslide causative factor, $\mathrm{A}$ is the presence and $\bar{A}$ is the absence of the landslides. The magnitude of positive weight $\left(\mathrm{Wi}^{+}\right)$is an indicator for the positive correlation between the presence of a desired class of the causative factor and the landslides. On the other hand, the negative weight $\left(\mathrm{Wi}^{-}\right)$indicates the absence of a desired class of the causative factor and shows the level of negative correlation. Table 1 and Table 2 show the spatial relationship between each indicator and the landslides for active and dormant landslide

\begin{tabular}{|c|c|c|c|c|c|c|c|}
\hline Factor & Class & Pixels in Domain & Landslide Pixel & Frequency Ratio & $\mathbf{W}^{+}$ & $\mathbf{W}^{-}$ & $\mathbf{W}_{\mathbf{f}}$ \\
\hline \multirow[t]{5}{*}{ DVI } & $-1951-502.996$ & 5753762 & 26043 & 2.946 & -0.740 & 0.056 & -0.684 \\
\hline & $502.996-908.243$ & 10065677 & 26051 & 1.687 & -0.364 & 0.061 & -0.303 \\
\hline & $908.243-1290.976$ & 15134013 & 27086 & 1.168 & -0.111 & 0.036 & -0.076 \\
\hline & $1290.976-1651.196$ & 17285810 & 8123 & 0.307 & 0.187 & -0.088 & 0.099 \\
\hline & $1651.196-3790$ & 10905079 & 3311 & 0.198 & 0.328 & -0.091 & 0.237 \\
\hline \multirow[t]{5}{*}{ NDVI } & $-1-0.223$ & 4064525 & 18818 & 3.029 & -0.827 & 0.041 & -0.786 \\
\hline & $0.223-0.435$ & 5269539 & 17989 & 2.236 & -0.690 & 0.048 & -0.642 \\
\hline & $0.435-0.6$ & 10428465 & 21768 & 1.369 & -0.280 & 0.051 & -0.229 \\
\hline & $0.6-0.725$ & 20926130 & 21038 & 0.660 & 0.036 & -0.020 & 0.016 \\
\hline & $0.725-1$ & 18779348 & 11001 & 0.385 & 0.309 & -0.181 & 0.128 \\
\hline \multirow[t]{5}{*}{ SAVI } & $-1.835-0.335$ & 4024556 & 18816 & 3.042 & -0.811 & 0.040 & -0.771 \\
\hline & $0.335-0.653$ & 5201071 & 18062 & 2.262 & -0.676 & 0.047 & -0.629 \\
\hline & $0.653-0.899$ & 10354953 & 21833 & 1.375 & -0.275 & 0.050 & -0.225 \\
\hline & $0.899-1.088$ & 20821701 & 20995 & 0.658 & 0.035 & -0.020 & 0.016 \\
\hline & $1.088-1.499$ & 18742193 & 10908 & 0.380 & 0.304 & -0.178 & 0.126 \\
\hline \multirow[t]{5}{*}{ OSAVI } & $-1.419-0.260$ & 4023434 & 18923 & 3.060 & -0.814 & 0.040 & -0.774 \\
\hline & $0.260-0.505$ & 5200335 & 18066 & 2.263 & -0.674 & 0.047 & -0.627 \\
\hline & $0.505-0.696$ & 10357174 & 21767 & 1.371 & -0.274 & 0.050 & -0.224 \\
\hline & $0.696-0.842$ & 20813325 & 20897 & 0.656 & 0.035 & -0.019 & 0.015 \\
\hline & $0.842-1.160$ & 18750101 & 10961 & 0.382 & 0.304 & -0.178 & 0.126 \\
\hline \multirow[t]{5}{*}{ Tree Irregularities } & Very Low & 35513411 & 61748 & 1.152 & -0.238 & 0.270 & 0.032 \\
\hline & Low & 14003828 & 13931 & 0.660 & 0.319 & -0.120 & 0.199 \\
\hline & Medium & 6976363 & 8341 & 0.793 & 0.277 & -0.043 & 0.235 \\
\hline & High & 2832024 & 4806 & 1.124 & 0.063 & -0.003 & 0.060 \\
\hline & Very High & 695318 & 1752 & 1.668 & -0.115 & 0.001 & -0.114 \\
\hline
\end{tabular}
activity.

Table 1. Spatial relationship between each indicator and the landslides for the FR and WoE (active landslide) 
The International Archives of the Photogrammetry, Remote Sensing and Spatial Information Sciences, Volume XLII-4/W16, 2019 6th International Conference on Geomatics and Geospatial Technology (GGT 2019), 1-3 October 2019, Kuala Lumpur, Malaysia

Table 2. Spatial relationship between each indicator and the landslides for the FR and WoE (dormant landslide)

\begin{tabular}{|c|c|c|c|c|c|c|c|}
\hline Factor & Class & Pixels in Domain & Landslide Pixel & Frequency Ratio & $\mathbf{W}^{+}$ & $\mathbf{W}^{-}$ & $\mathbf{W}_{\mathbf{f}}$ \\
\hline \multirow[t]{5}{*}{ DVI } & $-1951-502.996$ & 5753762 & 26043 & 2.946 & -0.740 & 0.056 & -0.684 \\
\hline & $502.996-908.243$ & 10065677 & 26051 & 1.687 & -0.364 & 0.061 & -0.303 \\
\hline & $908.243-1290.976$ & 15134013 & 27086 & 1.168 & -0.111 & 0.036 & -0.076 \\
\hline & $1290.976-1651.196$ & 17285810 & 8123 & 0.307 & 0.187 & -0.088 & 0.099 \\
\hline & $1651.196-3790$ & 10905079 & 3311 & 0.198 & 0.328 & -0.091 & 0.237 \\
\hline \multirow[t]{5}{*}{ NDVI } & $-1-0.223$ & 4064525 & 18818 & 3.029 & -0.827 & 0.041 & -0.786 \\
\hline & $0.223-0.435$ & 5269539 & 17989 & 2.236 & -0.690 & 0.048 & -0.642 \\
\hline & $0.435-0.6$ & 10428465 & 21768 & 1.369 & -0.280 & 0.051 & -0.229 \\
\hline & $0.6-0.725$ & 20926130 & 21038 & 0.660 & 0.036 & -0.020 & 0.016 \\
\hline & $0.725-1$ & 18779348 & 11001 & 0.385 & 0.309 & -0.181 & 0.128 \\
\hline \multirow[t]{5}{*}{ SAVI } & $-1.835-0.335$ & 4024556 & 18816 & 3.042 & -0.811 & 0.040 & -0.771 \\
\hline & $0.335-0.653$ & 5201071 & 18062 & 2.262 & -0.676 & 0.047 & -0.629 \\
\hline & $0.653-0.899$ & 10354953 & 21833 & 1.375 & -0.275 & 0.050 & -0.225 \\
\hline & $0.899-1.088$ & 20821701 & 20995 & 0.658 & 0.035 & -0.020 & 0.016 \\
\hline & $1.088-1.499$ & 18742193 & 10908 & 0.380 & 0.304 & -0.178 & 0.126 \\
\hline \multirow[t]{5}{*}{ OSAVI } & $-1.419-0.260$ & 4023434 & 18923 & 3.060 & -0.814 & 0.040 & -0.774 \\
\hline & $0.260-0.505$ & 5200335 & 18066 & 2.263 & -0.674 & 0.047 & -0.627 \\
\hline & $0.505-0.696$ & 10357174 & 21767 & 1.371 & -0.274 & 0.050 & -0.224 \\
\hline & $0.696-0.842$ & 20813325 & 20897 & 0.656 & 0.035 & -0.019 & 0.015 \\
\hline & $0.842-1.160$ & 18750101 & 10961 & 0.382 & 0.304 & -0.178 & 0.126 \\
\hline \multirow[t]{5}{*}{ Tree Irregularities } & Very Low & 35513411 & 61748 & 1.152 & -0.238 & 0.270 & 0.032 \\
\hline & Low & 14003828 & 13931 & 0.660 & 0.319 & -0.120 & 0.199 \\
\hline & Medium & 6976363 & 8341 & 0.793 & 0.277 & -0.043 & 0.235 \\
\hline & High & 2832024 & 4806 & 1.124 & 0.063 & -0.003 & 0.060 \\
\hline & Very High & 695318 & 1752 & 1.668 & -0.115 & 0.001 & -0.114 \\
\hline
\end{tabular}

\subsection{Validation of Landslide Activity Probability Models}

Validation of the produced landslide activity probability maps reveals the reliability of the results. The 'success rate' and 'prediction rate' methods are used in the validation process of map. The success rate allows to determine how well the resultant maps have classified the areas of existing landslides. However, this may be not sufficient for evaluation of the model's predictability, since the dataset utilized in the modelling. Therefore, prediction rate using the validation dataset (30\% of the landslide inventory) can explain how well the models to predict future landslides.

ROC is a popular method that can show the success and prediction curves of the output. This method provide a graph of 'sensitivity' versus 'specificity'. Sensitivity indicates as the ratio of unstable pixels above a desired threshold that correctly predicted by the model over the total observed unstable pixels and specificity is the ratio of stable pixels below the desired threshold that correctly predicted by the model over the total observed stable pixels. The AUC is calculated as the total area of polygons between the thresholds as

$$
A U C=\sum_{i=1}^{n+1} \frac{1}{2} \sqrt{\left(x_{i}-x_{i+1}\right)^{2}} \cdot\left(y_{i}+y_{i+1}\right)
$$

where $x i$ is (1-specificity) and $y i$ is sensitivity at the threshold $i$. An AUC value in the range of $0.90-1.00$ is considered as excellent, 0.80-0.90 indicates good, 0.70-0.80 fair, 0.60-0.70 poor, and 0.50-0.60 fail accuracy of the model (Hasanat et al., 2010) 
The International Archives of the Photogrammetry, Remote Sensing and Spatial Information Sciences, Volume XLII-4/W16, 2019 6th International Conference on Geomatics and Geospatial Technology (GGT 2019), 1-3 October 2019, Kuala Lumpur, Malaysia

\section{RESULTS AND DISCUSSION}

The results of this study are divided into two (2) type of activity i.e. active and dormant landslide probability map for each method as shown in Figure 2 to Figure 5. All the generated maps were classified into three classes i.e. low probability, medium probability, and high probability. Figure 6 and Figure 7 show the validatuin results for both methods with different landslide activities.

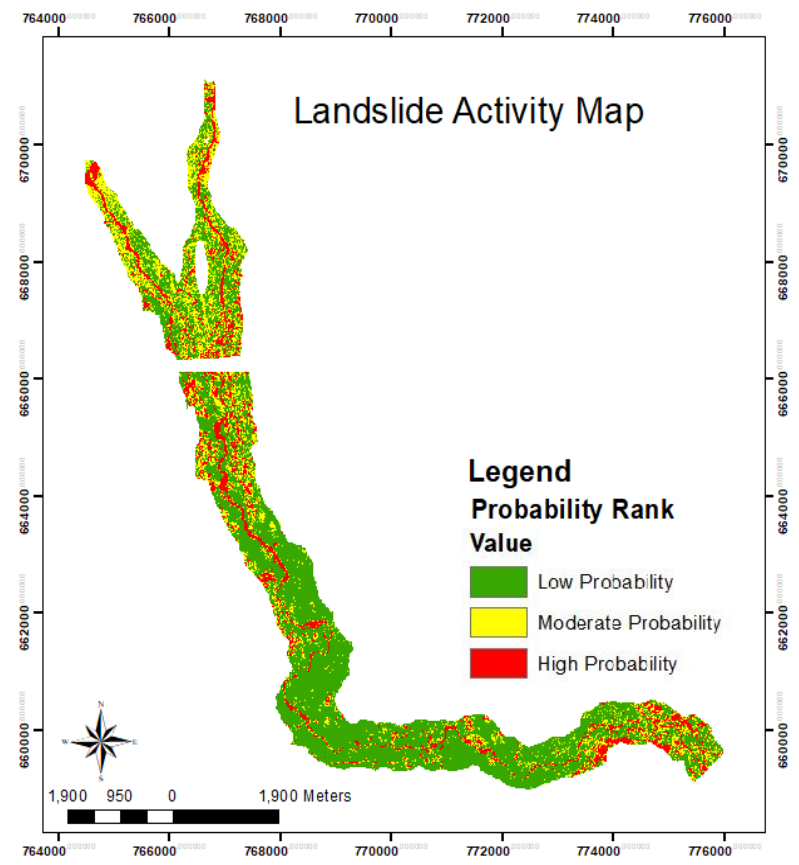

Figure 2. Active landslide probability map using FR method

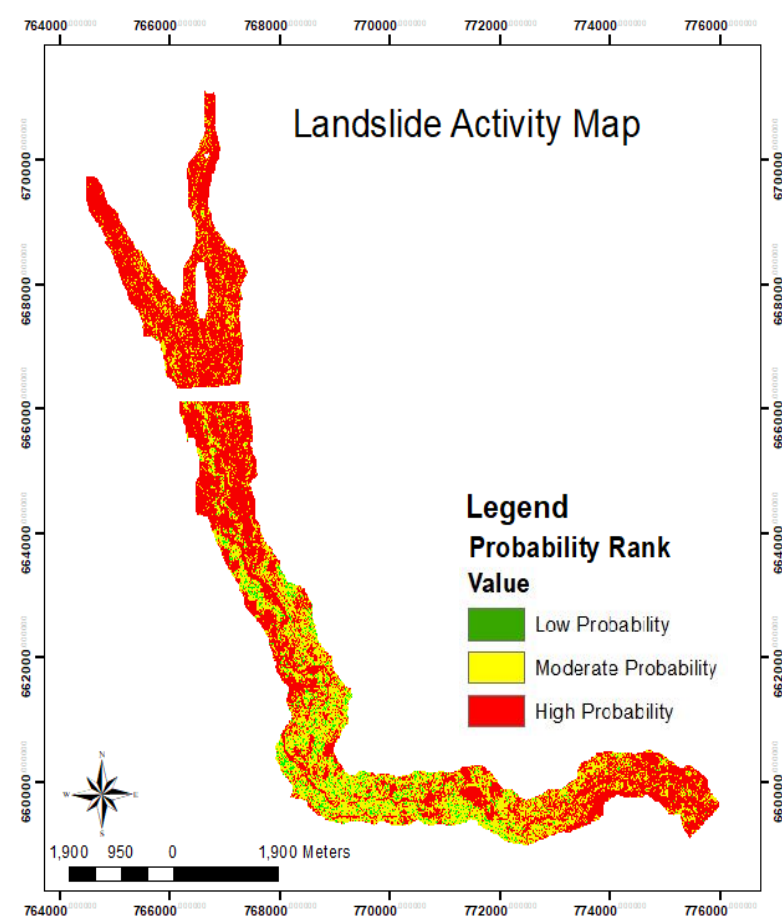

Figure 3. Dormant landslide probability map using FR method

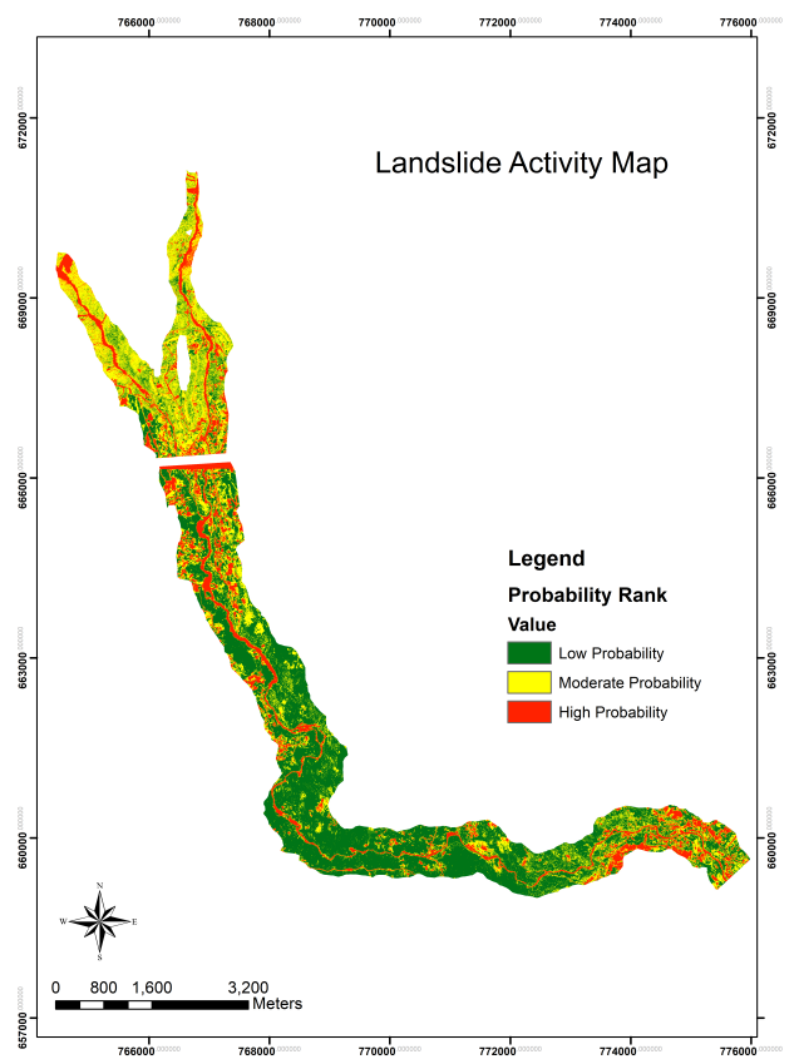

Figure 4. Active landslide probability map using WoE method

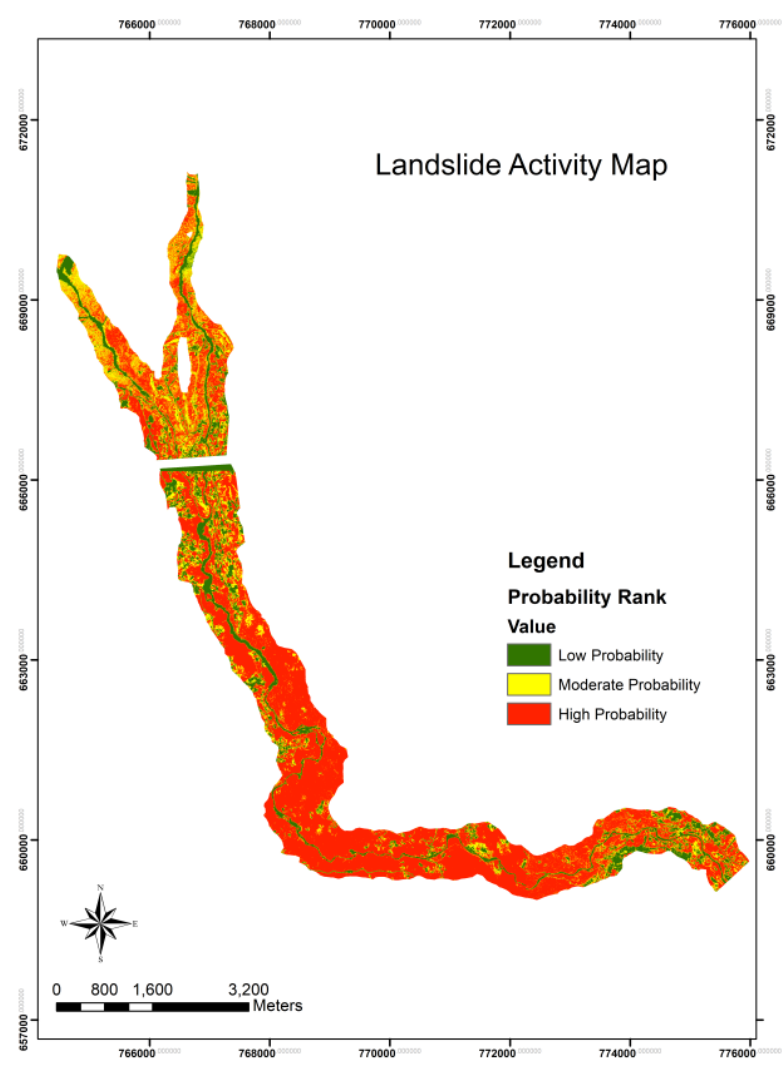

Figure 5. Dormant landslide probability map using WoE method 
ROC Curve for Active Landslide

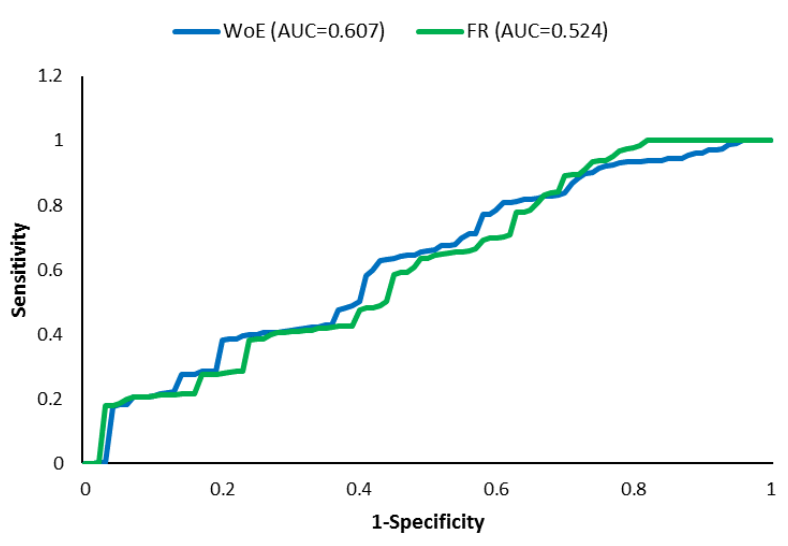

(a)
ROC Curve for Dormant Landslide

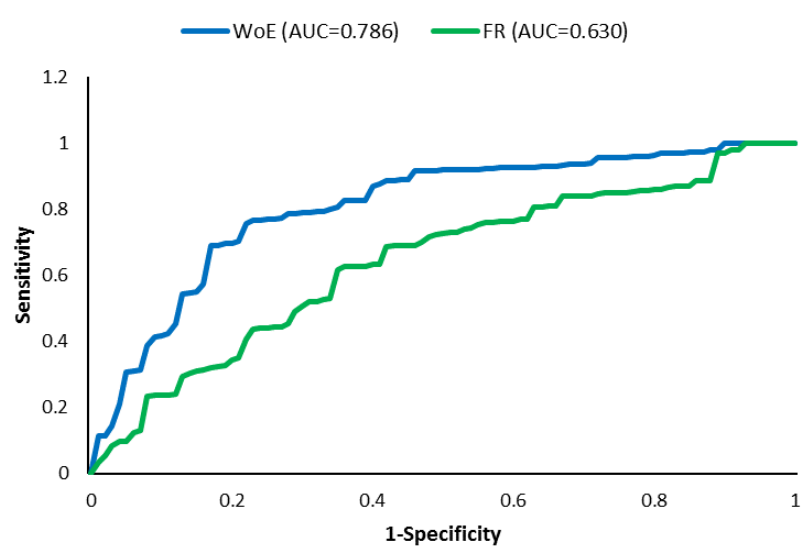

(b)

Figure 6 . The success rate for (a) active and (b) dormant landslide activities for different methods by ROC curve

\section{ROC Curve for Active Landslide}

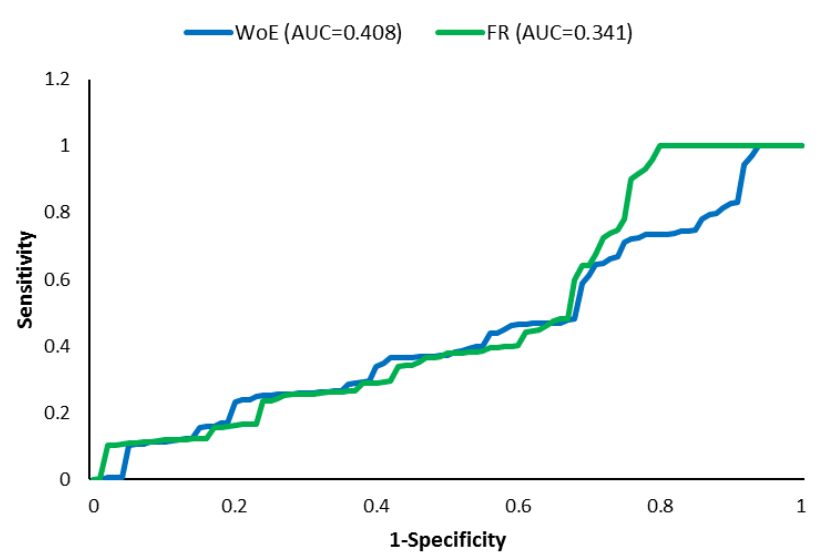

(a)

\section{ROC Curve for Dormant Landslide}

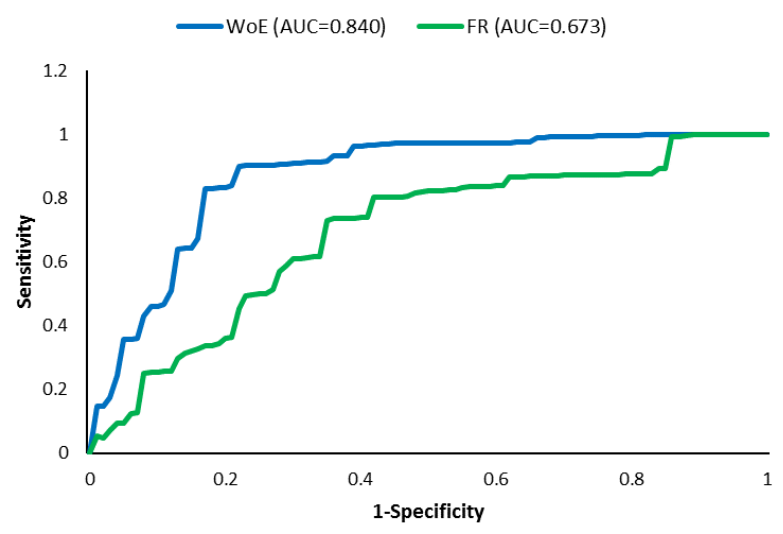

(b)

Figure 7. The prediction rate for (a) active and (b) dormant landslide activities for different methods by ROC curve

According to the results obtained, WoE method give more reliable results compared to FR method for both landslide activities. Similar cases for prediction rates where WoE still give better results in predicting landslide activity. The results also indicate that dormant activity recorded much better result than active landslide

\section{CONCLUSION}

Analysing vegetation anomaly patterns using remotely sensed data is a new approach of mapping and analysing landslide activity based on different landslide activity. Previously, many studies conducted an interpretation of morphological and drainage pattern for landslide activity identification. Different approach was taken in this study by focussing in the vegetation anomalies pattern. This study implements a procedure in generating landslide activity probability map from related vegetation indicator that obtained using remote sensing data. This procedure was done by characterizing the weight obtained from the landslide activity probability maps. The performances of the landslide activity probability map generated using frequency ration and weight of evidence approach were evaluated using success rate and prediction rate. The results revealed that vegetation anomalies as the indicator of analysing landslide activity is reliable as it gave good value for success rate especially for dormant landslide. The results obtained vary across different landslide activity, type and depth.

\section{ACKNOWLEDGEMENTS}

We would like to express our gratitude to Minerals and Geoscience Department for the remote sensing data and experts in the landslides mapping and inventory process. Special thanks to the experts from various departments including Minerals and Geoscience Department, Public Works Department, PLAN@Malaysia, and Universiti Malaysia Sabah. This work also is financed by Universiti Teknologi Malaysia, Ministry of Higher Education of Malaysia, GUP grant vot number Q.J130000.2527.19H43, and Zamalah/ Institutional Scholarship 


\section{REFERENCES}

Afeni, T. B., and Cawood, F. T., 2013. Slope monitoring using total station: what are the challenges and how should these be mitigated? South African Journal of Geomatics, 2(1), 41-53.

Artese, S., and Perrelli, M., 2018. Monitoring a Landslide with High Accuracy by Total Station: A DTM-Based Model to Correct for the Atmospheric Effects. Geosciences, 8(2), 46.

Berardino, P., Fornaro, G., Lanari, R., and Sansosti, E., 2002. A new algorithm for surface deformation monitoring based on small baseline differential SAR interferograms. IEEE Transactions on Geoscience and Remote Sensing, 40(11), 2375-2383.

Bianchini, S., Raspini, F., Ciampalini, A., Lagomarsino, D., Bianchi, M., Bellotti, F., and Casagli, N., 2017. Mapping landslide phenomena in landlocked developing countries by means of satellite remote sensing data: the case of Dilijan (Armenia) area. Geomatics, Natural Hazards and Risk, 8(2), 225-241.

Bibi, T., Razak, K. A., Rahman, A. A., and Latif, A., 2017. Spatio Temporal Detection and Virtual Mapping of Landslide Using High-Resolution Airborne Laser Altimetry (Lidar) in Densely Vegetated Areas of Tropics. In International Archives of the Photogrammetry, Remote Sensing \& Spatial Information Sciences (Vol. 42).

Bonham-Carter, G. F., Agterberg, F. P., and Wright, D. F., 1988. Integration of geological datasets for gold exploration in Nova Scotia. Photogrammetric Engineering and Remote Sensing, 54(11), 1585-1592.

Booth, A. M., Roering, J. J., and Perron, J. T., 2009. Automated landslide mapping using spectral analysis and high-resolution topographic data: Puget Sound lowlands, Washington, and Portland Hills, Oregon. Geomorphology, 109(3-4), 132-147.

Castagnetti, C., Bertacchini, E., Corsini, A., and Capra, A. 2013. Multi-sensors integrated system for landslide monitoring: critical issues in system setup and data management. European Journal of Remote Sensing, 46(1), 104-124.

Chen, Q., 2007. Airborne Lidar Data Processing and Information Extraction. Photogrammetric Engineering and Remote Sensing, 73(2), 109-112.

Chen, W., Chai, H., Sun, X., Wang, Q., Ding, X., and Hong, H., 2016. A GIS-based comparative study of frequency ratio, statistical index and weights-of-evidence models in landslide susceptibility mapping. Arabian Journal of Geosciences, 9(3), 204.

Cigna, F., Del Ventisette, C., Liguori, V., Casagli, N., Lasaponara, R., Vlcko, J., and Meisina, C., 2011. Advanced radar-interpretation of InSAR time series for mapping and characterization of geological processes. Natural Hazards \& Earth System Sciences, 11(3).

Corsini, A., Castagnetti, C., Bertacchini, E., Rivola, R., Ronchetti, F., and Capra, A., 2013. Integrating airborne and multi-temporal long-range terrestrial laser scanning with total station measurements for mapping and monitoring a compound slow moving rock slide. Earth Surface Processes and
Landforms, $\quad 38(11)$,

https://doi.org/10.1002/esp.3445

Ding, Q., Chen, W., and Hong, H., 2017. Application of frequency ratio, weights of evidence and evidential belief function models in landslide susceptibility mapping. Geocarto International, 32(6), 619-639.

Gaidzik, K., María Teresa Ramírez-Herrera, M. B., Leshchinsky, B. A., Olsen, M., and Regmi, N. R., 2017. Landslide manual and automated inventories, and susceptibility mapping using LIDAR in the forested mountains of Guerrero, Mexico. Geomatics, Natural Hazards and Risk, 5705(December), 1-26. https://doi.org/10.1080/19475705.2017.1292560

Gleyzes, M. A., Perret, L., and Kubik, P., 2012. Pleiades system architecture and main performances. International Archives of the Photogrammetry, Remote Sensing and Spatial Information Sciences, 39(1), 537-542.

Guzzetti, F., Carrara, A., Cardinali, M., and Reichenbach, P., 1999. Landslide hazard evaluation: A review of current techniques and their application in a multi-scale study, Central Italy. Geomorphology, 31(1-4), 181-216. https://doi.org/10.1016/S0169-555X(99)00078-1

Guzzetti, F., Mondini, A. C., Cardinali, M., Fiorucci, F., Santangelo, M., \& Chang, K. T., 2012. Landslide inventory maps: New tools for an old problem. Earth-Science Reviews, 112(1-2), 42-66.

https://doi.org/10.1016/j.earscirev.2012.02.001

Haneberg, W. C., Cole, W. F., \& Kasali, G., 2009. Highresolution lidar-based landslide hazard mapping and modeling, UCSF Parnassus Campus, San Francisco, USA. Bulletin of Engineering Geology and the Environment, 68(2), 263-276.

Hansen, A., 1984. Engineering geomorphology: the application of an evolutionary model of Hong Kong's terrain. Zeitschrift Für Geomorphologie, 51, 39-50.

Hasanat, M. H. A., Ramachandram, D., and Mandava, R., 2010. Bayesian belief network learning algorithms for modeling contextual relationships in natural imagery: a comparative study. Artificial Intelligence Review, 34(4), 291-308.

Haugerud, R. A., Harding, D. J., Johnson, S. Y., Harless, J. L., Weaver, C. S., and Sherrod, B. L., 2003. High-resolution lidar topography of the Puget Lowland, Washington. GSA Today, 13(6), 4-10.

Hooper, A., Segall, P., and Zebker, H., 2007. Persistent scatterer interferometric synthetic aperture radar for crustal deformation analysis, with application to Volcán Alcedo, Galápagos. Journal of Geophysical Research: Solid Earth, 112(B7).

Jaboyedoff, M., Choffet, M., Derron, M.-H., Horton, P., Loye, A., Longchamp, C., Pedrazzini, A., 2012. Preliminary Slope Mass Movement Susceptibility Mapping Using DEM and LiDAR DEM BT - Terrigenous Mass Movements: Detection, Modelling, Early Warning and Mitigation Using Geoinformation Technology. In B. Pradhan \& M. Buchroithner (Eds.) (pp. 109-170). Berlin, Heidelberg: Springer Berlin Heidelberg. https://doi.org/10.1007/978-3-642-25495-6_5 
Jaboyedoff, M., Oppikofer, T., Abellán, A., Derron, M. H., Loye, A., Metzger, R., and Pedrazzini, A., 2012. Use of LIDAR in landslide investigations: A review. Natural Hazards, 61(1), 5-28. https://doi.org/10.1007/s11069-010-9634-2

Joyce, K. E., Samsonov, S. V, Levick, S. R., Engelbrecht, J., and Belliss, S., 2014. Mapping and monitoring geological hazards using optical, LiDAR, and synthetic aperture RADAR image data. Natural Hazards, 73(2), 137-163.

Lee, S., and Pradhan, B., 2007. Landslide hazard mapping at Selangor, Malaysia using frequency ratio and logistic regression models. Landslides, 4(1), 33-41.

Lepore, C., Kamal, S. A., Shanahan, P., and Bras, R. L., 2012. Rainfall-induced landslide susceptibility zonation of Puerto Rico. Environmental Earth Sciences, 66(6), 1667-1681.

Lyons, N. J., Mitasova, H., and Wegmann, K. W. 2014. Improving mass-wasting inventories by incor,porating debris flow topographic signatures. Landslides, 11(3), 385-397.

Martha, T. R., Kerle, N., Jetten, V., van Westen, C. J., and Kumar, K. V., 2010. Characterising spectral, spatial and morphometric properties of landslides for semi-automatic detection using object-oriented methods. Geomorphology, 116(1-2), 24-36.

McCalpin, J., 1984. Preliminary age classification of landslides for inventory mapping. In Proceedings 21st annual Enginnering Geology and Soils Engineering Symposium (pp. 5-6).

Mondal, S., and Maiti, R., 2013. Integrating the analytical hierarchy process (AHP) and the frequency ratio (FR) model in landslide susceptibility mapping of Shiv-khola watershed, Darjeeling Himalaya. International Journal of Disaster Risk Science, 4(4), 200-212.

Park, S., Choi, C., Kim, B., and Kim, J., 2013. Landslide susceptibility mapping using frequency ratio, analytic hierarchy process, logistic regression, and artificial neural network methods at the Inje area, Korea. Environmental Earth Sciences, 68(5), 1443-1464.

Pawluszek, K., Borkowski, A., and Tarolli, P., 2017. Towards the optimal pixel size of DEM for automatic mapping of landslide areas. In International Archives of the Photogrammetry, Remote Sensing \& Spatial Information Sciences. https://doi.org/10.5194/isprs-archives-XLII-1-W1-83-2017

Pellicani, R., and Spilotro, G., 2015. Evaluating the quality of landslide inventory maps: comparison between archive and surveyed inventories for the Daunia region (Apulia, Southern Italy). Bulletin of Engineering Geology and the Environment, 74(2), 357-367.

Pirasteh, S., and Li, J., 2018. Developing an algorithm for automated geometric analysis and classification of landslides incorporating LiDAR-derived DEM. Environmental Earth Sciences, 77(11), 414.

Poli, D., Remondino, F., Angiuli, E., and Agugiaro, G., 2013. Evaluation of Pleiades-1a triplet on Trento testfield. International Archives of Photogrammetry, Remote Sensing and Spatial Information Sciences, XL-1 W, 1, 287-292.
Reis, S., Yalcin, A., Atasoy, M., Nisanci, R., Bayrak, T., Erduran, M., ... Ekercin, S., 2012. Remote sensing and GISbased landslide susceptibility mapping using frequency ratio and analytical hierarchy methods in Rize province (NE Turkey). Environmental Earth Sciences, 66(7), 2063-2073.

Rosi, A., Tofani, V., Tanteri, L., Stefanelli, C. T., Agostini, A., Catani, F., and Casagli, N., 2018. The new landslide inventory of Tuscany (Italy) updated with PS-InSAR: geomorphological features and landslide distribution. Landslides, 15(1), 5-19.

Rott, H. (2009). Advances in interferometric synthetic aperture radar (InSAR) in earth system science. Progress in Physical Geography, 33(6), 769-791.

Scaioni, M., Longoni, L., Melillo, V., and Papini, M., 2014. Remote sensing for landslide investigations: An overview of recent achievements and perspectives. Remote Sensing, 6(10), 9600-9652. https://doi.org/10.3390/rs6109600

Simeoni, L., Ferro, E., and Tombolato, S., 2015. Reliability of Field Measurements of Displacements in Two Cases of ViaductExtremely Slow Landslide Interactions. In Engineering Geology for Society and Territory-Volume 2 (pp. 125-128). Springer.

Skilodimou, H., Bathrellos, G., Koskeridou, E., Soukis, K., and Rozos, D., 2018. Physical and anthropogenic factors related to landslide activity in the Northern Peloponnese, Greece. Land, 7(3), 85 .

Stiros, S. C., Vichas, C., and Skourtis, C., 2004. Landslide monitoring based on geodetically derived distance changes. Journal of Surveying Engineering, 130(4), 156-162.

Tating, F. F., Hack, H., and Jetten, V. G., 2013. Weathering and detorioration as quantitative factors in slope design in humid tropical areas: case study Northern Kota Kinabalu, Sabah, Malaysia. Newsletter (Ingeokring), 33(1), 22-28.

Tongkul, F., 1987. Sedimentology and structure of the Crocker Formation in the Kota Kinabalu Area, Sabah, East Malaysia.

Tongkul, F., 2015. The 2015 Ranau Earthquake: Cause and Impact. Sabah Society Journal, 32, 1-28.

Tsai, Z.-X., You, G. J.-Y., Lee, H.-Y., and Chiu, Y.-J., 2012. Use of a total station to monitor post-failure sediment yields in landslide sites of the Shihmen reservoir watershed, Taiwan. Geomorphology, 139, 438-451.

Van Eeckhaut, M., D., Poesen, J., Verstraeten, G., Vanacker, V., Nyssen, J., Moeyersons, J., ... Vandekerckhove., 2007. Use of LiDAR-derived images for mapping old landslides under forest. Earth Surface Processes and Landforms, 32(5), 754-769.

Varnes, D. J., 1978. Slope movement types and processes. Special Report, 176, 11-33.

Wood, J. L., Harrison, S., and Reinhardt, L., 2015. Landslide inventories for climate impacts research in the European Alps. Geomorphology, 228, 398-408.

\section{Revised August 2019}

